\title{
AS-BUILT MODELING AND VISUAL SIMULATION OF TUNNELS USING REAL-TIME TBM POSITIONING DATA
}

\author{
Xiaodong Wu, Ming Lu, Sheng Mao \\ University of Alberta \\ Dept. of Civil \& Environmental Engineering \\ Edmonton, AB T6G 2W2, CANADA
}

\author{
Xuesong Shen \\ University of New South Wales \\ School of Civil and Environmental Engineering \\ Sydney, NSW 2052, AUSTRALIA
}

\begin{abstract}
To fulfill the needs of construction quality, progress control and sustainable development of the underground space, it is desirable to collect and visualize as-built tunnel information in real time. In the current practice, the as-built model of a tunnel is produced either by using advanced technologies like 3D laser scanning after construction ends, or by employing specialist tunnel surveyors to directly measure the invert positions. However, limitations of commonly applied as-built tunnel survey methods are identified in terms of accuracy, cost, or modeling speed. In this paper, we propose a new approach to enabling as-built modeling and visualization of tunnels based on real-time TBM tracking and positioning data. With a tunnel alignment automation control system being implemented, the TBM is turned into a "sensor" to map out as-build information in real time, without incurring extra labor cost or survey equipment. The proposed approach was field-tested and preliminary findings are discussed.
\end{abstract}

\section{INTRODUCTION}

With the trend of global urbanization, more and more underground facilities are built in urban areas, of which a large percentage are transit and utility tunnels built by Tunnel Boring Machines (TBM). As we further develop the underground space, we also make it increasingly congested. Compared with above ground buildings, tunnels are invisible as they are buried underground. To fulfill the need of sustainable development of underground space, especially to avoid collisions between existing tunnels and tunnels to be built, we need to well-document positions of the as-built tunnels.

In addition, managing a tunneling project is not an easy task. Strict requirements on as-built alignment control are generally imposed for quality assurance. According to Megaw and Bartlett (1981), the acceptable tolerance for the as-built alignment of a metro tunnel can be as tight as $\pm 40 \mathrm{~mm}$. For a drainage tunnel, the tolerance is normally limited to $50 \mathrm{~mm}$ in both horizontal and vertical directions; the maximum deviation over a total length of a few kilometers must be controlled under $150 \mathrm{~mm}$ (The City of Edmonton 2012). As we cannot intuitively see the TBM and the as-built tunnel, keeping the alignment in tight margins along such a long distance is really challenging. To ensure the quality of the as-built tunnel, it is desirable to visualize the alignment of tunnel sections being built in real time with $\mathrm{mm}$ level accuracy.

In this paper, we propose a new approach for real-time visual simulation of the as-built tunnel relying on data collected by the deployed automation system for tunnel alignment control at no extra cost. The Virtual Laser Target Board (VLTB) TBM Guidance System (Shen et al. 2012) is used for data acquisition and transmission; the present research develops a program for as-built modeling and visual simulation. To validate the feasibility of our approach, a case study was carried out in a real-life drainage tunnel project in Edmonton, Alberta, which is presented in this paper. The limitation and future improvement are also discussed. 
Wu, Lu, Shen, and Mao

\section{LITERATURE REVIEW}

To visualize the as-built tunnel, the first step is to collect as-built data. In the current practice, as-built data are retrieved mainly in two ways, namely: by remote sensing techniques like 3D Laser Scanning and Ground Penetrating Radar, or by measuring the positions of concrete lining segments.

3D Laser Scanning is a technique that uses laser beams to profile the shape of a real-world object. It has been applied for the as-built modeling and some other geotechnical and operational applications in a drill and blast tunnel (Fekete, Diederichs, and Lato 2010), and also for the deformation analysis of a bored tunnel (van Gosliga, Lindenbergh, and Pfeifer 2006). With this technique, we can automatically retrieve $3 \mathrm{D}$ as-built models with high resolution and accuracy, but it is non-portable and the equipment cost is still high (Zhu, and Brilakis 2009). Besides, for a tunnel built by the TBM method, 3D laser scanning is only possible after the completion of the project, as there are many temporary facilities in the congested tunnel space during the construction stage.

Ground Penetrating Radar (GPR) has been widely applied since the 1970s (Metje etal. 2007). It is a geophysical method that uses radar pulses to map the underground. It can be used for locating a wide variety of buried pipes, from plastic pipes to metallic pipes. However, this technique is limited in several aspects. First, the performance of a GPR largely depends on electrical conductivities of soils at the site. If the soil conductivity is high, the radar signal attenuates very fast in the ground and the maximum penetration range would be greatly reduced. Second, the accuracy is normally about several feet, which is not enough for accurate as-built modeling. Third, interpretation of radar-gram is not simple, full of noises and uncertainties, and thus requires special training. (Ghassemi, Zoldy, and Javady 2010)

Apart from remote sensing technologies, a more straightforward approach is directly measuring the positions of concrete lining segments. Li and Zhu (2009) proposed an approach for modeling and visualization of underground structures, based on latest construction information available. It worked well in Shanghai Yangtze River Tunnel, a large twin-tube bored tunnel with an outer diameter of $15.0 \mathrm{~m}(\mathrm{Li}$, Zhu, and Zhen 2009). However, for a typical tunnel project, especially a small diameter one, position information of concrete lining segments is not readily available. The manual process of data acquisition and analysis is time-consuming and requires the expertise of specialist surveyors.

After we retrieve as-built data, the next step is to generate as-built models and draw these models on the screen. Borrmann and Jubierre (2013) proposed a multi-scale tunnel product model which preserves coherent geometry and semantics under different level of details, by making use of procedural geometry descriptions and explicitly defining dependencies between individual geometric objects. However, their model is generated by extruding cross-sections along a given axis, and is mainly targeted for the design and planning of a tunnel project. The present research is intended to generate a tunnel product model based on as-built data collected from the field as TBM advances. The TBM is taken as "sensor" to map out as-build in real time.

\section{PROPOSED METHODOLOGY}

To improve the current practice of as-built tunnel modeling, a new approach is proposed based on using real-time TBM positioning data. The modeling algorithm is illustrated, and several issues about visualizing the soil layers, tunnel, and related information are also presented.

\subsection{Illustrations of the Proposed Methodology}

In a tunneling site, the tunneling crew installs concrete lining segments behind the TBM ring by ring, just like masons lay bricks layer by layer. It is reasonably assumed that the position of the latest installed tunnel section are determined by the position (distance, line deviation, and grade deviation) and orientation angles (yawing and pitching angles) of the TBM, as illustrated in Figure 1. Refer to Wu et al. (2013) for more information about the algorithmic details. 
As the TBM moves forward, new tunnel sections are installed one by one along the advancing direction of the machine, and the as-built model is also updated correspondingly, as shown in Figure 2.
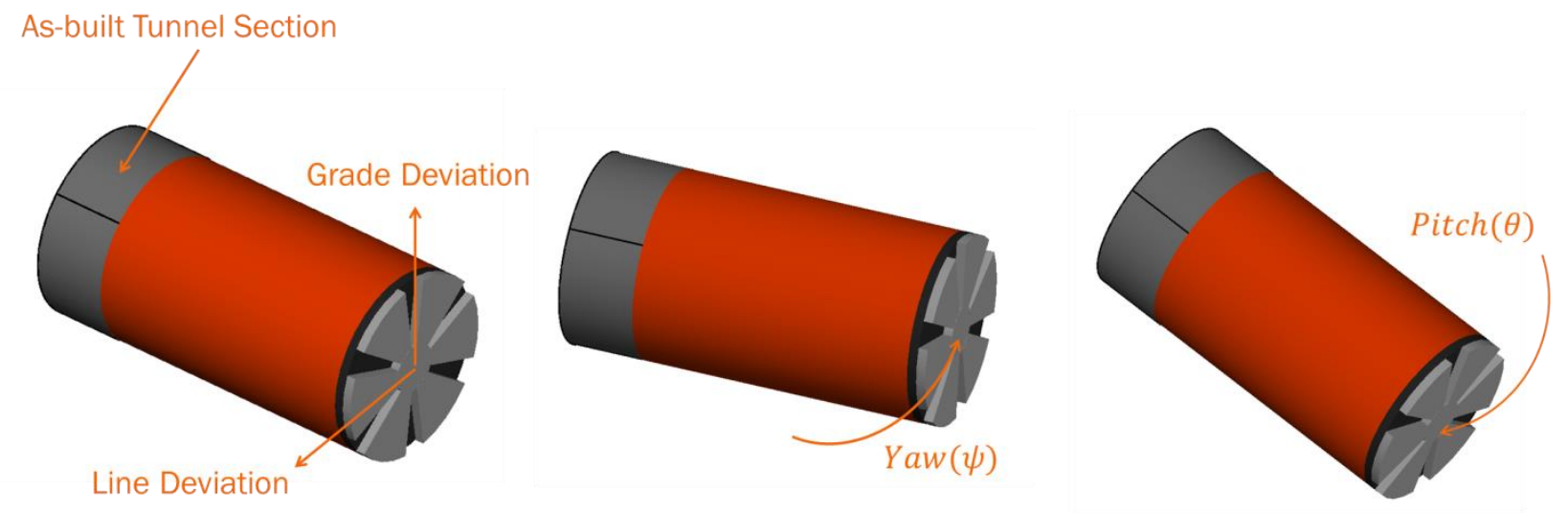

Figure 1: The latest installed tunnel section and the position and orientation angles of the TBM
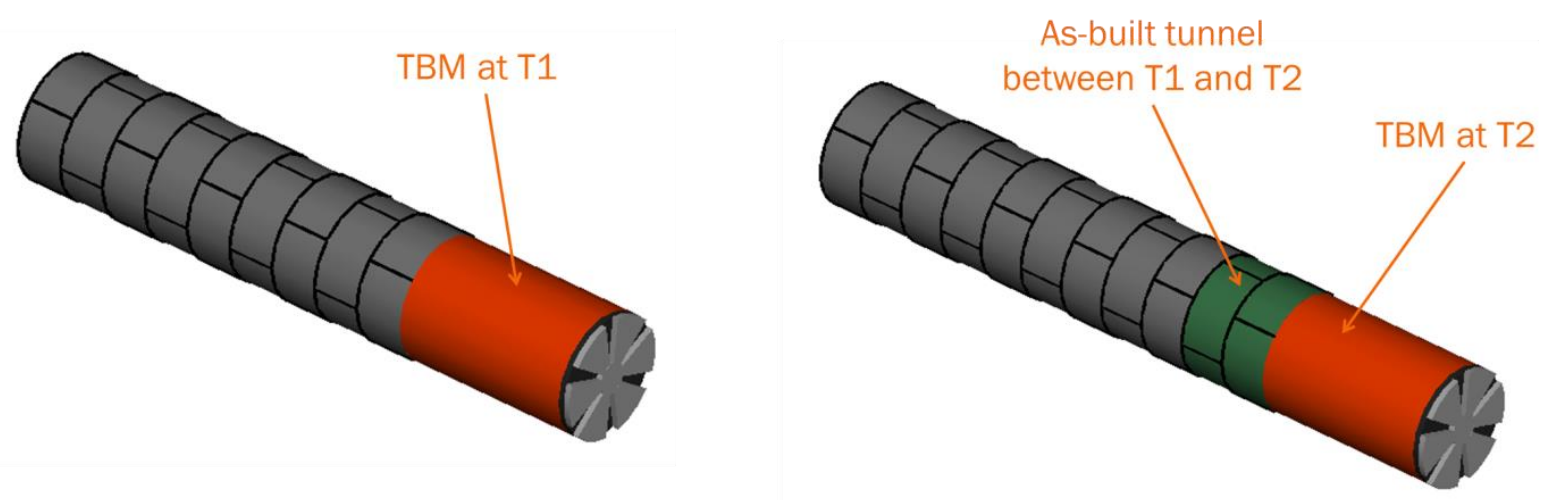

Figure 2: Updating the as-built tunnel model

\subsection{Visualization of Soil Layers, Tunnel, and Related Information}

\subsubsection{Visualization of Soil Layers}

In order to augment the visualization effect, it is desirable to visualize surrounding soil layers along the tunnel alignment. Figure 3 is a sample geological drawing from a project in the City of Edmonton. In this drawing, soil layers are interpolated between boreholes, which were drilled along the as-designed tunnel alignment before the construction of this project.

To visualize soil layers, we first divide the vertical cross section of the ground into several congruent, long and narrow rectangles. These rectangles are basic geometric units to be rendered by shaders (a shader is a program running on a graphics processing unit; it is used to do shading). In each rectangle, we assume that boundaries between different soil layers are linear. Thus, boundaries between soil layers can be represented by several groups of line segments. With the boundaries determined, we pass these rectangles to shaders, and apply multitexturing technique to render different soils. In Figure 4, Texture 1, Texture 2, and Texture 3 are used to render Soil Layer 1, Soil Layer 2, ad Soil Layer 3, respectively. 


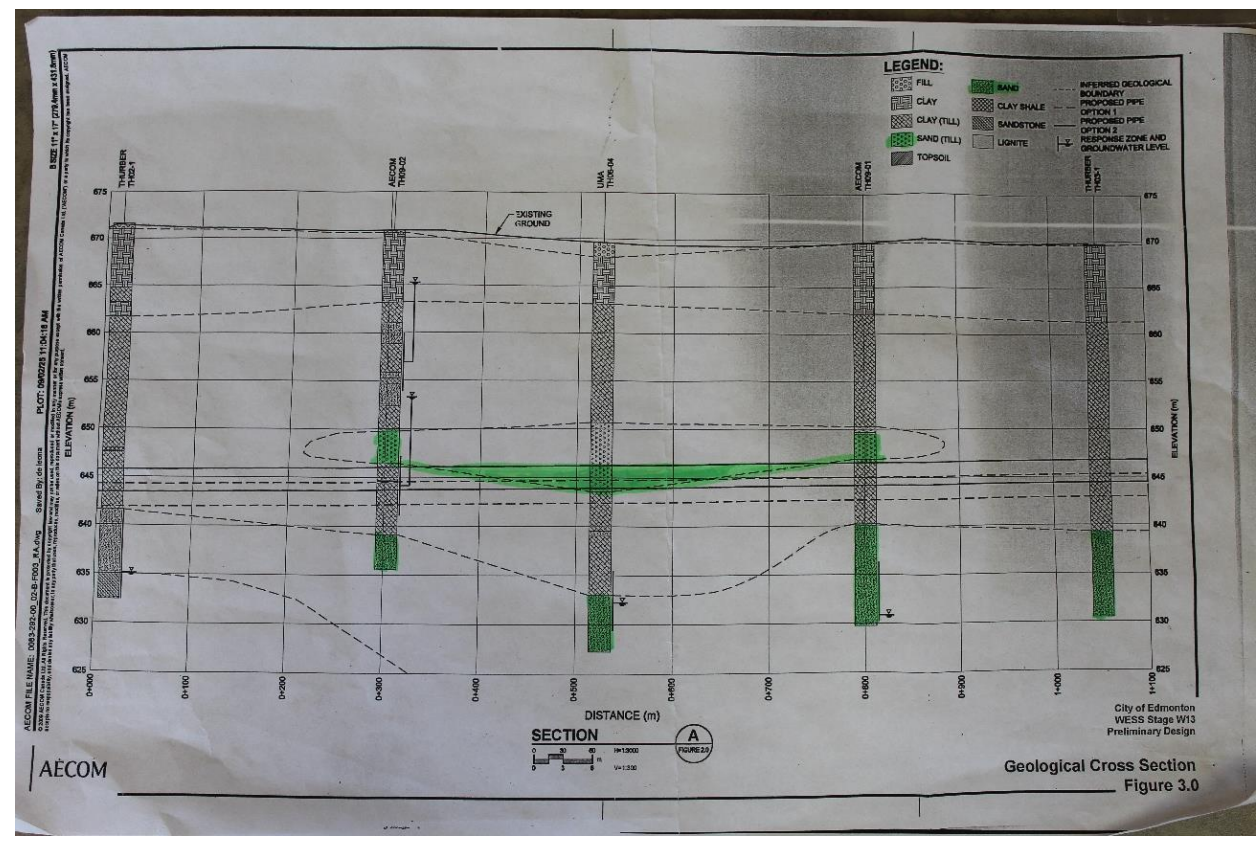

Figure 3: A sample geological drawing (Courtesy: City of Edmonton)

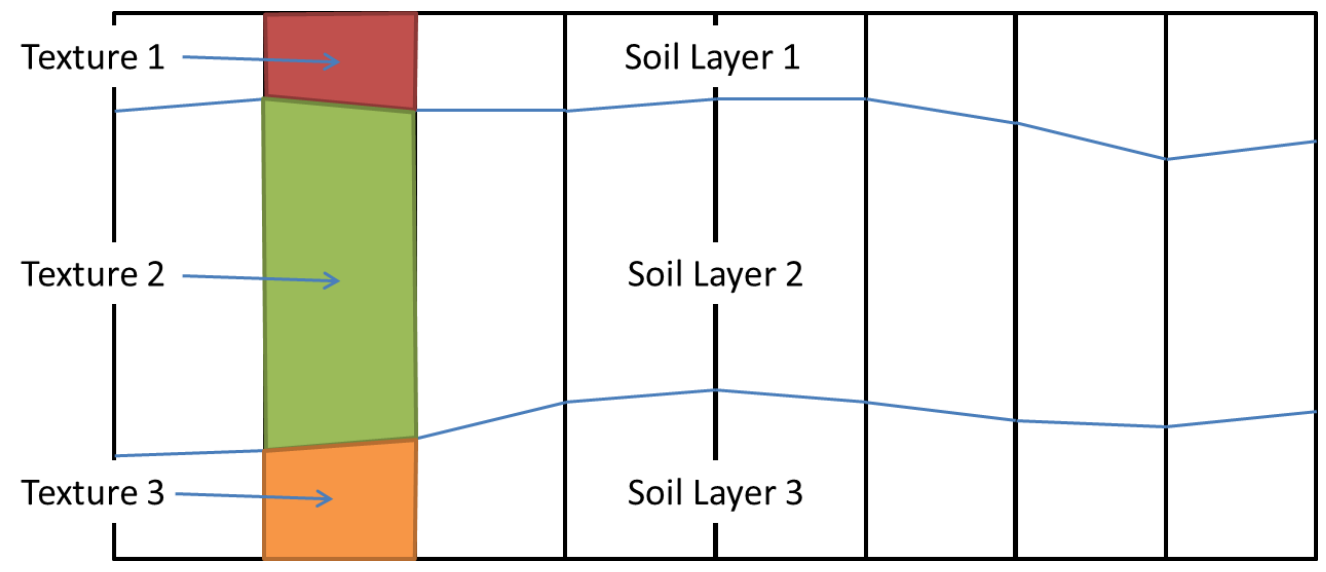

Figure 4: Illustration of soil layer visualization

\subsubsection{Cutting the Soil}

The reason for "cutting" the soil is to generate a more realistic visualization output, as if a real TBM would excavate soil as it moves forward..

One possible solution for cutting the soil objects might be directly splitting a rectangle into two polygons, as shown in Figure 5. This approach is straight forward at first glance, but it is actually difficult to be achieved. Instead, we apply Alpha Blending to virtually cut the soil. Several transparent polygons (with an alpha value of 0), called soil cutting objects, are generated in front of the rectangles, as shown in Figure 6, in which the white part represents soil excavated by the TBM. It is also worth mentioning that when we draw these objects, soil cutting objects are drawn before soil objects. As such, the particular portions of soil layers covered by soil cutting objects are automatically hidden by z-buffering. The result of this soil cutting algorithm is illustrated in Figure 7. 
Wu, Lu, Shen, and Mao

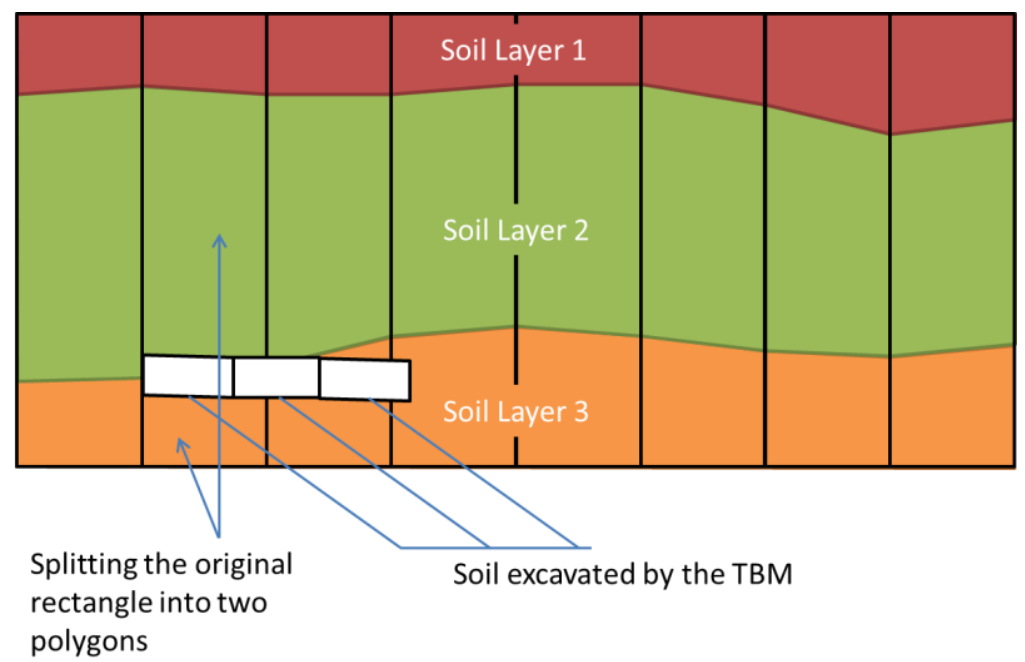

Figure 5: Cutting soil by splitting the rectangles

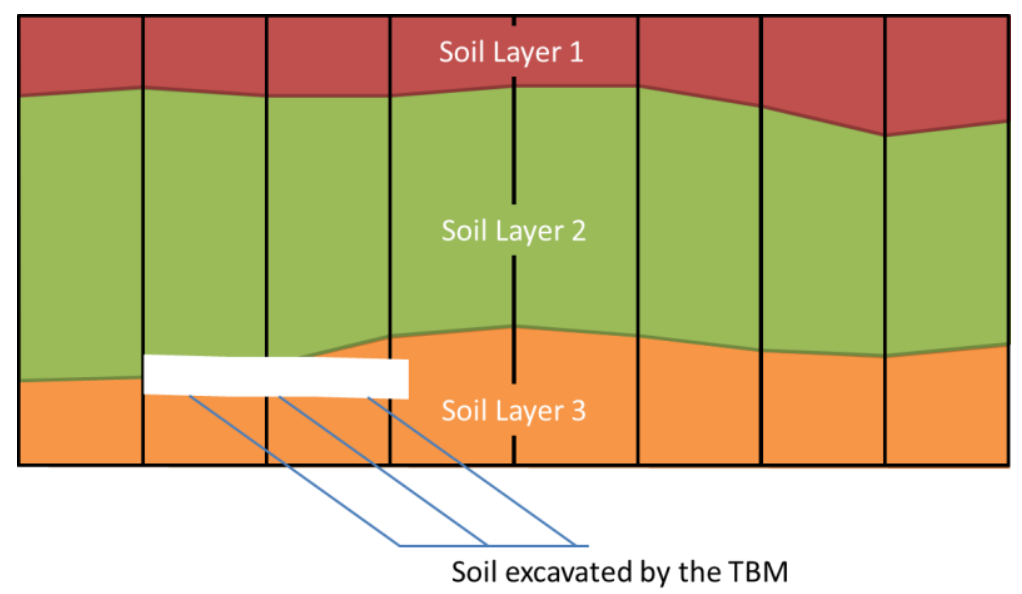

Figure 6: Virtually cutting soil by Alpha Blending

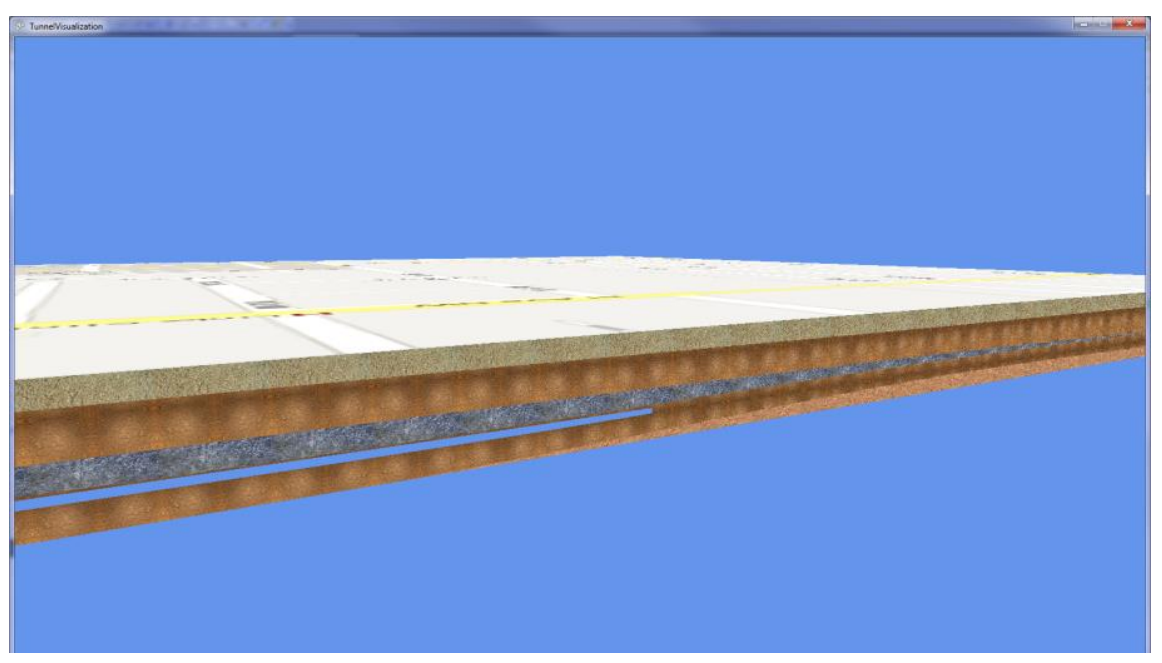

Figure 7: Effects of soil cutting 


\subsubsection{Visualization of the As-built Tunnel}

With the algorithm mentioned in Section 3.1, visualizing the as-built tunnel is simple and straightforward. First, we retrieve the position and orientation angles of the TBM at discrete time points $(\mathrm{t} 1, \mathrm{t} 2, \ldots \mathrm{tn})$. Then, the TBM's position and orientation angles are interpolated in a series of equally spaced points, with spacing equals to the width of a concrete lining segment, along the trajectory of the TBM. After that, concrete lining segments are created between two interpolated points. In the end, soil cutting objects, soil objects, the ground, and other related information are modeled and drawn on the screen.

\section{CASE STUDY}

\subsection{Project Description}

To test the VLTB TBM Automated Guidance System and the proposed as-built modeling and visual simulation approach, a drainage tunnel project of City of Edmonton, WESS Stage W13, was chosen as the test bed. The total length of the tunnel is $1012.6 \mathrm{~m}$ at grade $0.1 \%$ and the outer diameter is $2340 \mathrm{~mm}$ (about 8 feet). An 8-foot TBM was used to build this tunnel.

\subsection{TBM Guidance Systems}

To minimize risks of guidance errors, in this project, the contractor still relied on a traditional laser guidance system as the primary tool for positioning the TBM, while the VLTB TBM guidance system was tested for validation only. The results of our field testing are listed in Table 1, revealing that the differences between these two guidance systems are acceptable, and the VLTB guidance system is reliable. Note: (1) results from the laser system do not represent the true deviations $(30-40 \mathrm{~mm}$ errors according to experienced tunnel surveyors) but reliable benchmarks for cross checking VLTB results; (2) the VLTB guidance system integrates a robotic total station to realize high-precision point surveying at 2-3 $\mathrm{mm}$ accuracy.

Table 1 - Results of field testing

\begin{tabular}{ccccccccc}
\hline \multirow{2}{*}{ Date } & \multicolumn{2}{c}{ VLTB } & & \multicolumn{2}{c}{ Laser } & & \multicolumn{2}{c}{ Difference } \\
\cline { 2 - 3 } & $\begin{array}{c}\text { Line } \\
\text { Deviation }\end{array}$ & $\begin{array}{c}\text { Grade } \\
\text { Deviation }\end{array}$ & & $\begin{array}{c}\text { Line } \\
\text { Deviation }\end{array}$ & $\begin{array}{c}\text { Grade } \\
\text { Deviation }\end{array}$ & & $\begin{array}{c}\text { Line } \\
\text { Deviation }\end{array}$ & $\begin{array}{c}\text { Grade } \\
\text { Deviation }\end{array}$ \\
\hline $10 / 08 / 2012$ & -25 & 1 & & -5 & -20 & & -20 & 21 \\
$24 / 08 / 2012$ & 6 & 15 & & 5 & 15 & & 1 & 0 \\
$30 / 08 / 2012$ & -46 & -17 & & -5 & -15 & & -41 & -2 \\
$13 / 09 / 2012$ & 7 & -63 & & 15 & -30 & & -8 & -33 \\
$21 / 09 / 2012$ & -6 & -48 & & 0 & -20 & & -6 & -28 \\
$26 / 09 / 2012$ & -2 & -32 & & 6 & 15 & & -8 & -47 \\
$03 / 10 / 2012$ & -9 & -21 & & 10 & 20 & & -19 & -41 \\
$21 / 11 / 2012$ & 15 & -18 & & 0 & -40 & & 15 & 22 \\
\hline
\end{tabular}

\subsection{Testing the Proposed Approach}

Before the first field test, design information of W13 project, such as as-designed alignment, borehole information, was manually entered into a database. In each field test, new TBM positioning data were automatically inputted to the database. As TBM orientations were not always available due to limited visibility in the tunnel, it was reasonably assumed that the forward direction of the TBM was always parallel to the as-designed alignment, and the rolling angle of the machine (TBM rotates along the forward direction) was zero. The final visualization output is shown in Figure 8, which demonstrates the feasibility of our as-built modeling approach. 


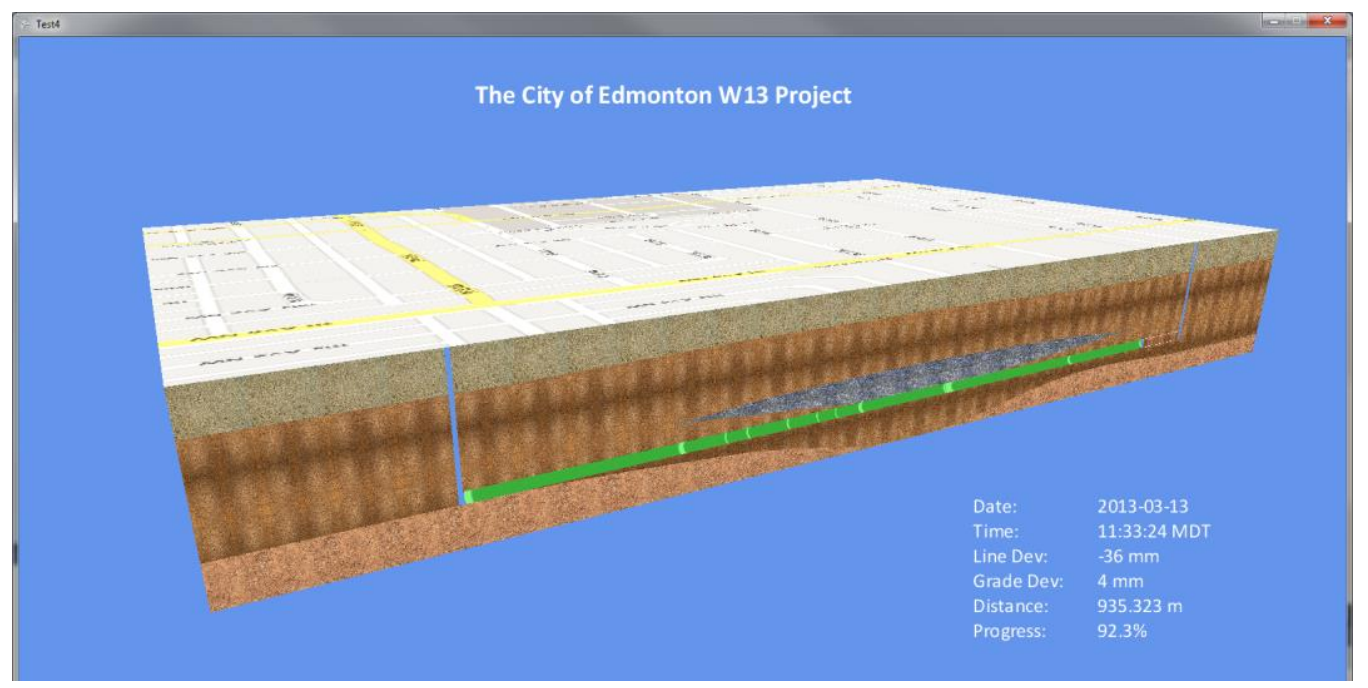

Figure 8: Final visualization output

\section{CONCLUSIONS}

As we further develop the underground space, we need to find out a way, fast, accurate and costeffectively, to keep record of the as-built tunnels. In recent years, several new technologies have been proposed to cope with this problem, but none of them is yet able to meet the requirements. In this paper, a new as-built tunnel modeling approach is proposed by using real-time TBM positioning data. A case study in Edmonton, Alberta was conducted to demonstrate the feasibility of our approach.

However, several factors are neglected in the presented research, such as the installation errors of concrete lining segments, the deformation of the tunnel under ground pressure, etc. In order to verify the accuracy of the proposed approach, the authors are planning to conduct a field survey for the inner profile of the tunnel on several sampled sections and cross check against the as-built model built by our approach.

\section{ACKNOWLEDGMENTS}

This research was substantially supported by Alberta Applied Research Funding Program of TECTERRA (1108-UNI-008). The writers thank Mr. Siri Fernando, Mr. Tim Schneider, Mr. Chris Pratt, Mr. Grant Fox, Mr. Rick Edge, Mr. Darsh Wimal Nawaratna, Mr. Michael Yu, Mr. Ray Davis and Mr. Junhao Zou of the City of Edmonton for their assistance in conducting field trials.

\section{REFERENCES}

Borrmann, A. and J. Jubierre. 2013. "A Multi-Scale Tunnel Product Model Providing Coherent Geometry and Semantics." In Computing in Civil Engineering (2013), 291-298: ASCE.

Fekete, Stephanie, Mark Diederichs, and Matthew Lato. 2010. "Geotechnical and Operational Applications for 3-Dimensional Laser Scanning in Drill and Blast Tunnels." Tunnelling and Underground Space Technology 25 (5): 614-628. doi:10.1016/j.tust.2010.04.008.

Ghassemi, M., D. Zoldy, and H. Javady. 2010. "Towards Precise Under Ground Mapping System in Canada." Portland, OR, Society for Mining, Metallurgy, and Exploration.

Li, Xiaojun, Hehua Zhu, and Lu Zhen. 2009. "Digitalization and Application of Shield Tunnels." Chinese Journal of Geotechnical Engineering 31 (9): 1456-1461. 
Li, Xiaojun and Hehua Zhu. 2009. "Modeling and Visualization of Underground Structures." Journal of Computing in Civil Engineering 23 (6): 348-354. doi:10.1061/(ASCE)0887-3801(2009)23:6(348).

Megaw, T. M. and J. V. Bartlett. 1981. Tunnels--Planning, Design, Construction. Ellis Horwood Series in Engineering Science. Vol. 1. New York: Chichester, West Sussex : Ellis Horwood.

Metje, N., P. R. Atkins, M. J. Brennan, D. N. Chapman, H. M. Lim, J. Machell, J. M. Muggleton, et al. 2007. "Mapping the Underworld - State-of-the-Art Review." Tunnelling and Underground Space Technology 22 (5-6): 568-586. doi:10.1016/j.tust.2007.04.002.

Shen, Xuesong, Ming Lu, Siri Fernando, and Simaan AbouRizk. 2012. "Tunnel Boring Machine Positioning Automation in Tunnel Construction." Eindhoven, The Netherlands, International Association for Automation and Robotics in Construction.

The City of Edmonton. "Design and Construction Standards, Drainage, Volume 3.", accessed 01/24, 2013, http://www.edmonton.ca/business_economy/documents/Volume_3_Drainage_.pdf.

van Gosliga, R., R. Lindenbergh, and N. Pfeifer. 2006. "Deformation Analysis of a Bored Tunnel by Means of Terrestrial Laser Scanning." Dresden, Germany, International Society for Photogrammetry and Remote Sensing Volume XXXVI, Part 5, 25-27 September.

Wu, X., M. Lu, S. Mao, and X. Shen. 2013. "Real-Time as-Built Tunnel Product Modeling and Visualization by Tracking Tunnel Boring Machines." Montreal, International Association for Automation and Robotics in Construction, August 11-15.

Zhu, Zhenhua and Ioannis Brilakis. 2009. "Comparison of Optical Sensor-Based Spatial Data Collection Techniques for Civil Infrastructure Modeling." Journal of Computing in Civil Engineering 23 (3): 170-177. doi:10.1061/(ASCE)0887-3801(2009)23:3(170).

\section{AUTHOR BIOGRAPHIES}

Xiaodong Wu is a M.Sc. student in the Department of Civil and Environmental Engineering at the University of Alberta. His research interests are visualization and automation in construction, specifically in the area of applying new technology to improve current construction processes. His email address is xwu10@ualberta.ca.

Ming Lu is an Associate Professor in the Department of Civil \& Environmental Engineering at the University of Alberta. He has been committed to achieving excellence in research and teaching in areas of construction engineering and project management. His research interests are construction surveying and automation, operations simulation and scheduling in construction. His email address is mlu6@ualberta.ca.

Xuesong Shen is a Lecturer in School of Civil and Environmental Engineering at the University of New South Wales. His research interests are Automation and Robotics in Construction Engineering. He has done extensive research on resource tracking in the construction field. His email address is x.shen@unsw.edu.au.

Sheng Mao is a Ph.D. student in the Department of Civil and Environmental Engineering at the University of Alberta. He received his M.Sc. degree in Geomatics Engineering from Wuhan University, China. His current research interest is to improve tunnel surveying and Tunnel Boring Machine guidance technology. His email address is mao1@ualberta.ca. 